\title{
Next generation sequencing in cancer: opportunities and challenges for precision cancer medicine
}

\section{Carmela Paolillo, Eric Londin \& Paolo Fortina}

To cite this article: Carmela Paolillo, Eric Londin \& Paolo Fortina (2016) Next generation sequencing in cancer: opportunities and challenges for precision cancer medicine, Scandinavian Journal of Clinical and Laboratory Investigation, 76:sup245, S84-S91, DOI: 10.1080/00365513.2016.1210331

To link to this article: http://dx.doi.org/10.1080/00365513.2016.1210331

曲 Published online: 17 Aug 2016.

Submit your article to this journal $\asymp$

Џ Article views: 6

Q View related articles $\asymp$

View Crossmark data 


\title{
Next generation sequencing in cancer: opportunities and challenges for precision cancer medicine
}

\author{
Carmela Paolillo ${ }^{\mathrm{a}}$, Eric Londin ${ }^{\mathrm{b}}$ and Paolo Fortina ${ }^{\mathrm{a}}$

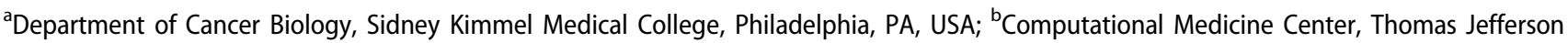 \\ University, Philadelphia, PA, USA
}

\begin{abstract}
Over the past decade, testing the genes of patients and their specific cancer types has become standardized practice in medical oncology since somatic mutations, changes in gene expression and epigenetic modifications are all hallmarks of cancer. However, while cancer genetic assessment has been limited to single biomarkers to guide the use of therapies, improvements in nucleic acid sequencing technologies and implementation of different genome analysis tools have enabled clinicians to detect these genomic alterations and identify functional and disease-associated genomic variants. Next-generation sequencing (NGS) technologies have provided clues about therapeutic targets and genomic markers for novel clinical applications when standard therapy has failed. While Sanger sequencing, an accurate and sensitive approach, allows for the identification of potential novel variants, it is however limited by the single amplicon being interrogated. Similarly, quantitative and qualitative profiling of gene expression changes also represents a challenge for the cancer field. Both RT-PCR and microarrays are efficient approaches, but are limited to the genes present on the array or being assayed. This leaves vast swaths of the transcriptome, including non-coding RNAs and other features, unexplored. With the advent of the ability to collect and analyze genomic sequence data in a timely fashion and at an ever-decreasing cost, many of these limitations have been overcome and are being incorporated into cancer research and diagnostics giving patients and clinicians new hope for targeted and personalized treatment. Below we highlight the various applications of next-generation sequencing in precision cancer medicine.
\end{abstract}

\section{ARTICLE HISTORY}

Accepted 9 March 2016

Published online 12 August 2016

\section{KEYWORDS}

Cancer genomics; circulating cancer cells; formalin-fixed paraffin-embedded; precision oncology

\section{Applications of Next-generation sequencing}

Identification of genomic variants that underlie susceptibility and causation of disease is of great interest. Next-generation sequencing (NGS), or massively parallel sequencing (MPS), is the 'catch-all' term used to describe a number of different modern sequencing technologies that allow sequencing of DNA and RNA much more quickly and cheaply than previously used Sanger sequencing $[1,2]$.

NGS allows for an efficient method to identify and characterize both known and novel variants at any location in the genome. Currently, approaches to do this can be as broad as whole-genome (WGS), whole-exome (WES), whole transcriptome (RNA-seq) and targeted sequencing of specific regions of the genome [3]. Many factors have to be taken into account in deciding which approaches could be the most suitable: budget, sample quality and quantity, depth of coverage needed, etc [4]. A comparison of these different approaches is summarized in Table 1.

In most cases a reference genome is available and the DNA derived from a specific individual is tested for known mutations or scanned for variation in entire regions, exomes or smaller target regions.

The most comprehensive approach to interrogate the genome is through whole genome sequencing (WGS). In an unbiased way, the entire genome can be sequenced and analyzed for the presence of mutations (both somatic and germline), copy number variants (CVNs), and other chromosomal structural variants including translocations, transversions and inversions. Furthermore, this analysis is not limited to just the coding regions of the genome, but also the non-coding portions. As interest in these regions of the genome gains, and functional mutations have been identified, WGS enables the interrogation of them. Despite these advantages, the ability to generate enough sequence coverage throughout the whole genome in a cost-effective manner remains a challenge. The high heterogeneity of many tumor types will result in many variants being present at low frequency and their identification would require a high read depth that is often not achieved with WGS due to the cost of generating sequence. Furthermore, the often high tumor heterogeneity caused by extracellular matrix and other non-cancerous cells can dilute the signal of a driver or pathological mutation. Last but not least, the large amount of data generated becomes a bioinformatic challenge, as vast amounts of computational resources are needed to process and store the data [5].

In comparison to WGS, targeted sequencing (TS) approaches offer a more affordable and specific method for

CONTACT Paolo Fortina paolo.fortina@jefferson.edu Cancer Genomics and Bioinformatics Laboratory, Sidney Kimmel Cancer Center, Bluemle Life Science Building 1009, Thomas Jefferson University, Philadelphia, PA 19107, USA

C 2016 Medisinsk Fysiologisk Forenings Forlag (MFFF) 
Table 1. Comparison of our Next Generation Sequencing approaches.

Whole Genome Sequencing (WGS)
- Comprehensiveness
- Detection of all the variants present in a genome
- Hypothestion of structural and CNVs
- Lowest depth of coverage
- Highest data complexity
- Required high quality
Transcriptome sequencing or RNA-seq
- Detection of variants present in the
- trascriptome and fusion genesRNA editing
- Differential expression
- Hard to identify variants in low expression transcript
- Required high quality RNA
Whole Exome Sequencing (WES)

- Interrogates protein-coding regions

- Cost-effective

- Gene discovery

- Required high quality

- Hard to identify structural variations

- Increasing coverage depth over WGS

Targeted Sequencing (TS)

- Regions of interest

- Highest depth of coverage

- Hypothesis-driven

- More manageable data storage and analysis

- Optimized also for low quality DNA (e.g. FFPE) identifying genomic variants. With targeted approaches, as much as whole exome, only a select few genes or the entire coding regions, respectively, are sequenced. While with these approaches, the ability to interrogate the entire genome is lost and much of the information will be missed, there are certain advantages to them over WGS. First, as only a small region of the genome is being sequenced, a much higher read depth can be achieved for a fraction of the cost compared to WGS. This increased coverage enables identification of low frequency mutations that otherwise would be missed with WGS. Second, a comprehensive approach will sequence many regions of the genome that are not needed for disease diagnostics or therapeutics. In fact, only a handful of genes have repeatedly been associated with cancers. Therefore, targeted cancer gene panels ranging from as little as a dozen to several hundred genes where mutations are more likely to occur in specific regions or hotspot, have been readily incorporated into a clinical setting for disease diagnostics $[6,7]$.

\section{NGS platforms and technologies}

DNA sequencing methods generally work by stopping the process of copying the template strand using dideoxynucleotides, reversible terminators or natural nucleotides [2]. Strategies for massively and ultrafast sequencing include sequencing-by-hybridization, nanopore sequencing and sequencing-by-synthesis (SBS). Most commercially available platforms use the SBS technology where the sequence of a template is inferred by stepwise primer elongation. The process involves immobilizing the sequencing templates and primers on a solid support followed by base primer extension and termination. The color of the fluorophore carried by the extended base is recognized and then the fluorescent tag and the 3-OH blocking group are removed and the steps are repeated. The whole process has been popularized as a second-generation sequencing technology on the Illumina platform. Several optical systems can be utilized to monitor synthesis of the complementary strand. In most cases four different fluorescently labeled nucleotides are involved, but recently Illumina introduced a three fluorescently labeled nucleotide system for the NextSeq sequencer. In this case a 2-channel system is required to detect the red (C) and green (T) signal, while the incorporation of $\mathrm{A}$ is detected in both channels as yellow and no signal is interpreted as $G$ incorporation [8].
Non-optical detection systems are available including semiconductor-based sequencing commercialized by Fisher Scientific (Waltham, MA). In the Ion Torrent, also an SBSbased sequencer, reactions take place in a semiconductor chip, which detects the hydrogen ions produced during DNA polymerization. Following clonal amplification, the DNA library fragment is poured sequentially with each nucleoside triphosphate and incorporated into the new strand by complementary to the nucleotide on the target strand. Each time a nucleotide is successfully added, a hydrogen ion is released, and is detected by the sequencer's $\mathrm{pH}$ sensor. The Ion torrent sequencing is the first commercial platform to use nonfluorescence and camera scanning making it a cost-effective tool compared to other methods. Its main disadvantage is the difficulty to decode repetitive sequences, such as, for example, a homopolymer repeat of length 6 which may generate a $\mathrm{pH}$ change indistinguishable from a homopolymer of length 8 [9].

All SBS sequencing systems rely on DNA amplification and therefore are unable to perform single-molecule sequencing. Helicos Biosciences previously reported a single-molecule technique; however, its dependence on reversible terminators limited it to the analysis of short DNA fragments [10].

Pacific Biosciences (Menlo Park, CA) solved the singlemolecule challenge by developing the zero-mode waveguide (ZMW) array, a nanostructured device that reduces the detection chamber volume to the zeptoliter $\left(10^{-21} \mathrm{~L}\right)$ range representing an improvement of three orders of magnitude over confocal fluorescence microscopy. At this resolution volume/resolution, an estimated single molecule in the detection layer provides a very low signal-to-noise ratio. To perform parallel sequencing, inside each ZMW, an active DNA polymerase with one molecule of single-stranded DNA template is immobilized on the bottom surface through which light can penetrate and create a visualization chamber that allows monitoring in real-time monitoring of the activity of the DNA polymerase activity as it traverses a single molecule. To allow uninterrupted monitoring of nucleotide incorporation, four discrete fluorescent dyes on a synthetic nucleotide's terminal phosphate group rather than on the base, are employed in the sequencing reaction [11-13].

A non-SBS, non-optical technology, single molecule sequencing referred to as nanopore sequencing works by feeding a small molecule through a membrane-spanning protein channel in a buffered ion solution. When a voltage is 
Table 2. A summary of widely used next-generation sequencers and their technologies.

\begin{tabular}{|c|c|c|c|c|c|c|}
\hline Company & Sequencer & $\begin{array}{c}\text { Library } \\
\text { amplification }\end{array}$ & Carrier & $\begin{array}{l}\text { Sequencing } \\
\text { technology }\end{array}$ & Detection method & Comments \\
\hline Illumina Inc & $\begin{array}{l}\text { MiniSeq } \\
\text { MiSeq } \\
\text { Hiseq } \\
\text { NextSeq }\end{array}$ & Bridge PCR & Flow cell & $\begin{array}{l}\text { Reversible termin- } \\
\text { ator SBS }\end{array}$ & $\begin{array}{l}\text { Optical detection of } \\
\text { fluorescence from } \\
\text { dye-labeled } \\
\text { nucleotides }\end{array}$ & $\begin{array}{l}\text { 75-600 bp } \\
\text { Capability: WES, WGS, tar- } \\
\text { get seq, WTS }\end{array}$ \\
\hline Life Technologies & $\begin{array}{l}\text { Ion PGM } \\
\text { Ion Proton }\end{array}$ & emPCR & Ion Chip & $\begin{array}{l}\text { Semiconductor- } \\
\text { based SBS }\end{array}$ & $\begin{array}{l}\text { Transistor-based detec- } \\
\text { tion of } \mathrm{H}^{+} \text {shift } \\
\text { after nucleotide } \\
\text { incorporation }\end{array}$ & $\begin{array}{l}200 \text { and } 400 \text { bp } \\
\text { Capability: WES, WTS, tar- } \\
\text { get seq }\end{array}$ \\
\hline Qiagen & GeneReader & NA & Flowcell & SBS & Fluorescence detection & $\begin{array}{l}12 \text { gene cancer test: } \\
\text { Actionable Insight Tumor } \\
\text { Panel }\end{array}$ \\
\hline Pacific Biosciences & $\begin{array}{l}\text { RS II } \\
\text { Sequel }\end{array}$ & NA & SMRT cell & $\begin{array}{l}\text { Single Molecule } \\
\text { Real Time } \\
\text { sequencing }\end{array}$ & $\begin{array}{l}\text { Real-time fluorescence } \\
\text { detection }\end{array}$ & $\begin{array}{l}\text { up to } 40,000 \text { bp } \\
\text { Capability: WES, WGS, WTS, } \\
\text { target seq, de novo gen- } \\
\text { ome assembly }\end{array}$ \\
\hline Oxford Nanopore & $\begin{array}{l}\text { MinION } \\
\text { PromethION } \\
\text { GridION }\end{array}$ & NA & $\begin{array}{l}\text { Protein } \\
\text { nanopore }\end{array}$ & $\begin{array}{l}\text { ssDNA nanopore- } \\
\text { based }\end{array}$ & $\begin{array}{l}\text { Change in electrical } \\
\text { Field }\end{array}$ & $\begin{array}{l}\text { Up to } 10,000 \mathrm{bp} \\
\text { Capability: WES, WGS, WTS, } \\
\text { target seq, de novo gen- } \\
\text { ome assembly }\end{array}$ \\
\hline Complete Genomics - BGI & $\begin{array}{l}\text { Revelocity } \\
\text { Sequencing } \\
\text { System }\end{array}$ & $\begin{array}{l}\text { Combinatorial } \\
\text { Probe-Anchor } \\
\text { Ligation (cPAL) }\end{array}$ & $\begin{array}{l}\text { DNA nano-ball } \\
\text { (DNB array) }\end{array}$ & $\begin{array}{l}\text { Ligation-based } \\
\text { CPAL } \\
\text { sequencing }\end{array}$ & fluorescence detection & Restricted to WGS WES \\
\hline
\end{tabular}

applied across the membrane, an ionic current is induced through the protein nanopore. As a molecule passes through the pore, one base at a time, it produces a measurable disturbance in the ion current providing information to decipher the sequence of the molecule. The technology is scalable and has been commercialized on a device, the size of a USB memory stick, the MinION, by Oxford nanopore (Oxford, UK) to distinguish between nucleotide bases [14]. The Oxford Nanopore's 'strand sequencing' advantages are that it can read much longer strands of DNA than other sequencing methods, requires unamplified DNA, removing the need for PCR and less sample. In principle these features make it possible for a doctor to read a patient's DNA directly from a blood sample [15]. A summary of widely used NGS sequencers and their technologies is shown in Table 2.

There are four core steps in the standard workflow associated with NGS: (1) sample preparation; (2) amplification; (3) sequencing; and (4) data analysis. In most cases, after nucleic acid extraction, DNA is fragmented to generate smaller strands by physical methods like acoustic shearing or by enzymatic methods. Based on the NGS-platform, the strands are ligated to double-stranded pieces of synthetic DNA referred to as adapters, enabling the sequence to become bound to a complementary counterpart for library construction by clonal bridge amplification or emulsion PCR. Platform-specific adapters allow multiplex samples to be clonally amplified being spatially arranged or separated. Numerous kits for making sequencing libraries from DNA and RNA are available commercially from a variety of vendors. Library size is determined by the desired insert size while optimal insert size is determined by the limitations of the NGS instrumentation and by the specific sequencing application such as WGS, WES, coding and non-coding RNA sequencing and target gene resequencing. Finally, a bioinformatics pipeline is required to process and analyze all the collected information and to detect the genetic variant by sequence alignment, quality assessment, variant calling and variant association.

For targeted genomic assays, several methods are available for capture and sequencing of specific genes and regions relevant to the tumor type. They can be subdivided in two main classes: (1) enrichment by amplification; and (2) enrichment by hybridization [16]. The former involves several locus-specific primer pairs and a multiplexed amplification reaction. Small amounts of DNA are required to achieve deep coverage of specific regions of interest. This type of panel typically interrogates discontinuous regions around hotspot mutations and not the entire coding sequence of the gene of interest. Therefore, this method is most suitable in testing FFPE samples and is not recommended for detection of structural alterations (CNVs and translocations). Enrichment by hybridization or hybridization capture requires more input and higher quality DNA. Therefore, it is most suitable for fresh or frozen samples where synthetic DNA or RNA probes, specific to the genomic area of interest, bind the complementary sequence on the genomic DNA, followed by target capture and amplification. This method can detect copy number gain and loss and selected structural rearrangements [16]. Several probe-captured based technologies are available (TruSeq and Nextera, Illumina, San Diego, CA; Sureselect and Haloplex, Agilent technologies, Santa Clara, CA). These methods are performed on a bench-top or production sequencer like Illumina or Ion Torrent.

Several studies have already tested and compared different enrichment technologies, and could be used as a guide in the selection of the most appropriate procedure. Comparisons have been made between a few technologies and data were analyzed using a variety of parameters including the percentage of targeted bases covered by probes and by sequence reads, e.g. design coverage and sensitivity, respectively, and the number of reads mapping to the targeted sequence, e.g. specificity. Uniformity and reproducibility or overall variation in per-base coverage over the targeted region and 
variation between replicates, respectively, were also taken into account $[17,18]$.

\section{Cancer panel-gene targeted sequencing: challenges and outcomes}

The use of NGS in cancer screening has generated a large catalog of potential somatic tumor mutations that cover different exons in a large number of genes, available for both solid and liquid tumors. An 'actionable' genomic mutation is defined when 'it is potentially targetable with a US Food and Drug Administration (FDA)-approved drug or other agent that can be used in early clinical trials' [19]. Serial singlegene testing could be time consuming especially for FFPE tumor biopsies; therefore, hot-spot based assays or cancer panels covering actionable variations that could affect patient's treatment choice are widely used to identify single validated variants $[20,21]$. Therefore, through a comprehensive genomic analysis, patients may benefit from genotypedirected therapy or genotype-matched clinical trials.

The decision about how and which genes to sequence requires consideration of the number of cases, cost, accessibility to matched normal tissue and turn-around-time. One option is to outsource the entire process to a commercial reference laboratory. A wide variety of commercially predesigned panels are available and are listed in Table 3 with the reference laboratory performing cancer targeted resequencing $[4,16]$. Most also can be customized with the addition of relevant genetic variants and non-coding sequence information such as promoters and/or regulatory regions. Furthermore, to provide more flexibility and allow screening of specific genes relevant only to a specific tumor type, most companies have made either large or small cancer-specific panels where the customer can select not only genes, but also which area of those genes have to be analyzed. However, setting up an in-house panel allows the laboratory the flexibility of adding new biomarkers and variants as soon as new evidence or clinical trials are available. In addition, the laboratory has access to all data (quality, frequencies, etc.), custom pipelines for bioinformatic analysis and results may be integrated with associated clinical information. Finally, once the assay is validated it can be used on other samples or optimized for other types of specimens.

\section{Tumor heterogeneity}

An emerging field of interest is the analysis of tumor heterogeneity, cell clonality and effects on therapy response. The possibility of easily accessing sample tumor cells over time allowed for the identification of a wide range of driver mutations in many NGS studies and also facilitated the investigation of tumor frequency over time [22]. Analysis of cancer genomes of solid tumors presents several challenges. Tumor biopsies are often arduous to obtain because of quantity and quality. They usually contain a mixture of tumor cells and non-tumor cells, and some of the tumors are highly heterogeneous [23]. Therefore, to achieve desirable detection sensitivity, a high coverage of sequencing may be required (500-1000X). To address this, custom-targeted NGS panels have been developed, especially for large numbers of samples where the optimal choice is to genotype the primary tumor, matched non-tumor tissue, and, if available, recurrent metastatic sites. One example is the MSK-IMPACT, a hybridization capture-based, next-generation sequencing assay for interrogating somatic alterations in 341 oncogenes and tumor suppressors in formalin-fixed, paraffin-embedded (FFPE) tumor specimens [24]. Patient-matched tumor and normal samples were sequenced and then sensitivity, specificity, and reproducibility of the MSK-IMPACT panel assessed through the validations on 284 known positive tumor samples with predefined point mutations and insertions/deletions variant detected at $500 \times$ coverage depth. Detection limit for low frequency variants in hotspot mutation and non-hotspot mutation was $2 \%$ and $5 \%$, respectively [24].

The main concerns about clinical genomics and the sequencing data generated is how they currently impact therapy decisions, whether they can lower the costs of health care, improve survival rate and/or improve quality of life. The number of publications reporting clinical utility of comprehensive genomic profiling in cancer patients is still

Table 3. Commercially available pre-designed panels and representative reference laboratories performing cancer-targeted resequencing.

\begin{tabular}{llr}
\hline Vendor & Assay name & No. of genes \\
\hline Illumina, Inc (San Diego, CA) & TruSight Cancer & 94 \\
& TruSight Tumor 15 & 15 \\
& TruSight Myeloid & 54 \\
Thermo Fisher Scientific (Waltham, MA) & TruSeq Amplicon Cancer Panel & 48 \\
& lon AmpliSeq Cancer Hotspot Panel v2 & 50 \\
Qiagen (Hilden, Germany) & lon Ampliseq Comprehensive Cancer Panel & 400 \\
Agilent Technologies (Wilmington, DE) & Actionable Inside Tumor Panel & 12 \\
& ClearSeq Comprehensive & 151 \\
& ClearSeq Cancer & 47 \\
Foundation Medicine ${ }^{\circledR}$, Inc (Cambridge, MA) & ClearSeq AML & 20 \\
University of Washington (Seattle, WA) & Cancer Research Panel & 47 \\
ParadigmDX (Phoenix, AZ) & Foundation One & 315 \\
ARUP Lab (Salt Lake City, UT) & UW-Oncoplex & 234 \\
Caris Life Science (Irving, TX) & PCDx & 114 \\
Knight Diagnostic Lab (Portland, OR) & Solid Tumor Mutation Pannel & 48 \\
PathGroup (Brentwood, TN) & MI Profiles & 46 \\
Life Technologies (Carlsbad, CA) & GeneTrails Cancer Gene Panel & 38 \\
\hline
\end{tabular}


limited. In June 2015 the American Association Cancer Research Precision Medicine Series conference took place to discuss the integration of NGS into clinical practice. One study highlighted potential benefits using precision medicine approaches [25]. A 100 gene-targeted panel was evaluated for identification of molecular targets in metastatic patients of diverse cancer types. The cohort of 72 cancer patients was subdivided into two groups; 36 patients received standard care and the other 36 were treated using a precision medicine approach. Progression-free survival (PFS) and total treatment costs were taken into account to establish if the precision medicine approach would improve PSF of the metastatic cancer patients without increasing healthcare costs. The precision medicine group showed an increase in PSF with comparable total costs [26]. In a second study, a 48 NGS gene panel was employed to analyze 1893 cancer patients with different histologies in a retrospective study. Although 13\% could not be analyzed due to low DNA quality or lack of sufficient FFPE material, $80 \%$ of all other tested samples showed at least one mutation. Unfortunately, only $5 \%$ of these patients followed a genotype-matched clinical trial, and did show a better response, emphasizing the need to improve on design of these kinds of trials [27].

\section{Tumor heterogeneity, drug resistance and liquid biopsy}

The intra-tumoral heterogeneity and clonal evolution under treatment selection pressure are two causes for tumor recurrences. Cancer cells in a slowly-proliferating or even 'dormant status' may continue to accumulate genetic and epigenetic alterations that may conceal metastases. Acquisition of resistance to therapy could be due to tumor heterogeneity or influenced by an appropriate reaction to treatment regimen.

NGS studies should be designed to detect heterogeneity and the dynamic status of the tumor. Unfortunately, solid biopsies do not fit this need, due to sample collection challenges including accessibility, especially during the course of the disease. Most often the procedure for sampling is invasive and even if available, the region obtained may not be representative of overall tumor heterogeneity.

\section{Circulating tumor cells (CTCs) and circulating cell- free tumor DNA (cfDNA)}

Circulating tumor cells (CTCs) and circulating cell-free tumor DNA (cfDNA) can be a source of cancer material, representative of disease status and compatible with repetitive, non-invasive sampling [28,29]. Use of cfDNA and CTCs enable testing patients over time and may overcome the need for serial solid biopsies.

The cfDNA are released into the bloodstream from tumor tissue and from lysis of CTCs. For this reason cfDNA and CTCs must be considered as two separate entities [30]. Several challenges are associated with cfDNA analysis since it represents fragmented DNA (160-180 bp) [31], is usually present at low concentrations and can be mixed with non- tumor DNA. The pre-analytical steps can have significant impact on analysis and the final yield. In addition, high sensitivities are often required to detect variation expected at a frequency of $<0.1 \%$. One of the best methods to achieve this level of sensitivity is the digital PCR (dPCR) droplet system, especially when a limited number of loci need to be evaluated [32]. However, characterization of rare variants is often a daunting task to track down by NGS because rare variants may be difficult to distinguish from sequencing errors. Template tagging methods such as Safe-Sequencing System, or Safe-SeqS [33] and tagged-amplicon deep sequencing, or TAm-Seq [34], have been developed to distinguish errors from real variants to allow comprehensive cancer genomic profiles [34]. The most immediate clinical application is in identification of genomic alterations to guide selection of target therapies and to monitor in real time during disease progression and therapy.

CTCs are, like the cfDNA, extensively studied for their potential clinical utility. They represent a rare population of cells in the background of $10^{6}-10^{7}$ nucleated blood cells and they require a critical enrichment step before their detection and characterization. Although they were first described by T. R. Ashworth in 1869 [35] technologies have only recently been developed to address enrichment challenges in terms of capture efficiency/recovery rate, blood sample capacity, cell viability and purity. The main strategy to enrich CTCs can be based on biological features (like cell surface marker expression) or on physical properties (like size, density or deformability). The only currently FDA-approved technology is CellSearch ${ }^{\circledR}$ (Veridex, Rarithan, NJ), an EpCam-based capture method followed by immuno-fluorescent staining using epithelial markers such as cytokeratin 8, 18, 19 and leucocyte-specific marker CD45. However, this technology cannot detect CTCs that may have undergone an epithelial to mesenchymal transition (EMT). This relevant subpopulation may exhibit molecular and functional stem-like features often correlated to chemo-resistance. The value of CTC detection using the CellSearch ${ }^{\circledR}$ was demonstrated in metastatic breast, prostate and colon cancer patients [27,36,37]. In addition to the effort to characterize and detect CTCs, recently several studies have demonstrated mutational profiles of CTCs in various cancer types. In one study, CTCenriched fractions using CellSearch ${ }^{\circledR}$ from six metastatic colorectal cancer patients were analyzed on a 68 cancer panel NGS array, and all mutations found were confirmed as subclonal mutations in primary tumors and/or metastases [38]. Moreover, several new techniques to isolate and analyze single cells are allowing single CTC mutational analysis to better investigate and understand the correlation between tumor heterogeneity and drug resistance. DEParray ${ }^{\mathrm{TM}}$ was used to isolate single CTCs from the CellSearch CTCsenriched fraction, followed by single whole genome/transcriptome amplification [39] and targeted or comprehensive NGS analysis [40]. CTC-enriched cells from the CellSearch system and cfDNA were investigated in 48 patients with $\mathrm{ER}+$ positive metastatic breast cancer receiving systemic therapy [41]. This investigation involved 23 target genes with hot spot mutations in the following genes: ESR1, PIK3CA, TP53, FGFR1 and FGFR2. NGS detected three 
Table 4. NGS assay parameters recommended to validate molecular diagnostic test.

\begin{tabular}{|c|c|}
\hline Depth of coverage & $\begin{array}{l}\text { The minimum sequencing coverage of target region under standard assay conditions, for each type of variant, should be estab- } \\
\text { lished in order to achieve the required level of mutation detection. }\end{array}$ \\
\hline Limit of detection & The lower limit of mutation detection under standard assay conditions for different variants (SNVs, CNVs, insertion, deletion, etc.). \\
\hline Accuracy & The degree of concordance between NGS's sequences obtained with the assay and the reference sequence. \\
\hline Precision & The degree of result reproducibility by the assay across users and runs. \\
\hline Specificity & $\begin{array}{l}\text { The probability of the assay to not detect sequence variants where none are present among samples validation set } \\
\text { (false-positive rate). }\end{array}$ \\
\hline Sensitivity & Capability of the assay to detect true sequence variants among sample validation set (false-negative rate). \\
\hline Reproducibility & The capability of the assay to give consistent results within-run. \\
\hline Reportable range & Range of values over which the test is evaluated valid. \\
\hline Reference range & When a test has specific reference for designed population or study group. \\
\hline
\end{tabular}

activating mutations in ESR1, three hotspot mutations in PIK3CA and three in TP53 in baseline cfDNA. Only the ESR1 p.D538G mutation was found in one matched circulating tumor cell sample. This can be explained by the fact that only CTC pools were analyzed in which the predominant component is wild type, while the mutation was detected in cfDNA at only $1 \%$ [41]. In another study, a single CTC study on ERS1-activating mutations and their correlation with endocrine therapy resistance showed feasibility and potential clinical utility. ESR1 mutational status has been successfully performed on 72 single cells isolated from metastatic breast cancer patients, and mutations were reported in patients with an acquired endocrine-based therapy resistance [42]. The development of single-cell sequencing is making CTCs a potential target to assess prognosis, monitor response therapy and for rational selection of the best therapy. All these studies suggest that blood-based biomarkers can reveal uniquely the dynamics of primary tumor formation or metastases. CTCs and ct-DNA each can contribute differently to detection of somatic variation at a frequency of $1 \%$ or lower, which in most cases is impossible to differentiate from noise using a solid biopsy specimen.

\section{Clinical validation and ethical implications}

The integration of these NGS technologies in any clinical sequencing workflow requires analytic and clinical validation, stringent regulations and guidelines established by the agencies governing clinical laboratories. Clinical laboratories are subject to legal obligations designed to ensure that tests meet parameters for trueness, precision, sensitivity and specificity. Organizations like the College of American Pathologists (CAP) and the Association for Molecular Pathology (AMP) have defined assay parameters for low-throughput assays and have defined assay parameters (Table 4) for NGS sequencing implementation in diagnostic settings $[43,44]$.

One strategy to validate cancer NGS assays is to test several tumor specimens with known somatic variants (insertion-deletion, CNVs, SNVs, etc.) and detect that aberration using another possible sequencing platform. Human cell lines positive for somatic mutation or germ-line polymorphisms with already characterized changes also can be used [8]. The reference sample utilized for validation should mimic features of the clinical samples for which the NGS assay is being validated. The quality and quantity of the starting material should be comparable to the clinical sample used. Most cancer specimens are usually FFPE samples in which nucleic acids are compromised, especially in quality. Therefore, protocols must be optimized to deliver deepsequencing coverage for these kinds of specimens. Several synthetic standards are available and can be used for NGS validation. Theoretically, a synthetic standard or cell lines can be used for each gene and variant, especially for which one has a low allele frequency [8]. Cross-validation on different NGS platforms is also suggested for a new NGS clinical assay $[8,45]$.

Matched germ-line DNA is typically used as a normal control to distinguish inherited variants and to increase analytical sensitivity. There are ethical, social and legal implications in this kind of approach. The analysis can incidentally reveal germ-line susceptibility to cancer or other diseases (incidental findings) with significant consequences for the patient and family members. Therefore, ethical considerations are critical and genetic counseling should be available to properly educate the patients as well as relatives if required, about risk and benefit of each genetic test and informed consent should be signed. Guidelines about how to manage incidental findings in the clinical setting have been released by the American College of Medical Genetics and Genomics (ACMG) and the American Society of Clinical Oncology (ASCO) [8,46,47].

\section{Conclusions}

Since January 2015 the 'Precision Medicine' initiative has represented an attempt at disease prevention and treatment that utilizes an individual's variation in genes in order to select the most appropriate therapeutic strategy for each patient on the basis of individual variability. These approaches offer much promise, but much work is still needed to ensure sensitivity, specificity, timeliness, costeffectiveness and validity of such testing [48]. Furthermore, clear actionable clinical treatment strategies must be defined so that rationale for a precision medicine approach is clear.

\section{Disclosure statement}

The authors report no conflict of interest. The authors alone are responsible for the content and writing of the paper.

\section{Funding}

This work was supported in part by the Kimmel Cancer Center (Philadelphia, PA to PF). CP is supported by a Celsee Diagnostics Research Grant. 


\section{References}

1. Koboldt DC, Steinberg KM, Larson DE, Wilson RK, Mardis ER. The next-generation sequencing revolution and its impact on genomics. Cell 2013;155:27-38.

2. Shendure J, Ji H. Next-generation DNA sequencing. Nat Biotechnol 2008;26:1135-45.

3. Metzker ML. Emerging technologies in DNA sequencing. Genome Res 2005;15:1767-76.

4. Meldrum C, Doyle MA, Tothill RW. Next-generation sequencing for cancer diagnostics: a practical perspective. Clin Biochem Rev 2011;32:177-95.

5. Xuan J, Yu Y, Qing T, Guo L, Shi L. Next-generation sequencing in the clinic: promises and challenges. Cancer Lett 2013;340:284-95.

6. Roychowdhury S, Chinnaiyan AM. Translating genomics for precision cancer medicine. Annu Rev Genomics Hum Genet 2014;15:395-415.

7. Hagemann IS, Cottrell CE, Lockwood CM. Design of targeted, capture-based, next generation sequencing tests for precision cancer therapy. Cancer Genet 2013;206:420-31.

8. Luthra R, Chen H, Roy-Chowdhuri S, Singh RR. Next-generation sequencing in clinical molecular diagnostics of cancer: advantages and challenges. Cancers 2015;7:2023-36.

9. Rothberg JM, Hinz W, Rearick TM, Schultz J, Mileski W, Davey M, Leamon JH, Johnson K, Milgrew MJ, Edwards M, Hoon J, Simons JF, Marran D, Myers JW, Davidson JF, Branting A, Nobile JR, Puc BP, Light D, Clark TA, Huber M, Branciforte JT, Stoner IB, Cawley SE, Lyons M, Fu Y, Homer N, Sedova M, Miao X, Reed B, Sabina J, Feierstein E, Schorn M, Alanjary M, Dimalanta E, Dressman D, Kasinskas R, Sokolsky T, Fidanza JA, Namsaraev E, McKernan KJ, Williams A, Roth GT, Bustillo J. An integrated semiconductor device enabling non-optical genome sequencing. Nature 2011;475:348-52.

10. Harris TD, Buzby PR, Babcock H, Beer E, Bowers J, Braslavsky I, Causey M, Colonell J, Dimeo J, Efcavitch JW, Giladi E, Gill J, Healy J, Jarosz M, Lapen D, Moulton K, Quake SR, Steinmann K, Thayer E, Tyurina A, Ward R, Weiss H, Xie Z. Single-molecule DNA sequencing of a viral genome. Science 2008;320:106-9.

11. Korlach J, Marks PJ, Cicero RL, Gray JJ, Murphy DL, Roitman DB, Pham TT, Otto GA, Foquet M, Turner SW. Selective aluminum passivation for targeted immobilization of single DNA polymerase molecules in zero-mode waveguide nanostructures. Proc Natl Acad Sci U S A 2008;105:1176-81.

12. Eid J, Fehr A, Gray J, Luong K, Lyle J, Otto G, Peluso P, Rank D, Baybayan P, Bettman B, Bibillo A, Bjornson K, Chaudhuri B, Christians F, Cicero R, Clark S, Dalal R, Dewinter A, Dixon J, Foquet M, Gaertner A, Hardenbol P, Heiner C, Hester K, Holden D, Kearns G, Kong X, Kuse R, Lacroix Y, Lin S, Lundquist P, Ma C, Marks P, Maxham M, Murphy D, Park I, Pham T, Phillips M, Roy J, Sebra R, Shen G, Sorenson J, Tomaney A, Travers K, Trulson M, Vieceli J, Wegener J, Wu D, Yang A, Zaccarin D, Zhao P, Zhong F, Korlach J, Turner S. Real-time DNA sequencing from single polymerase molecules. Science 2009;323:133-8.

13. Westbrook CJ, Karl JA, Wiseman RW, Mate S, Koroleva G, Garcia K, Sanchez-Lockhart M, O'connor DH, Palacios G. No assembly required: full-length MHC class I allele discovery by PacBio circular consensus sequencing. Hum Immunol 2015;76:891-6.

14. Ashton PM, Nair S, Dallman T, Rubino S, Rabsch W, Mwaigwisya S, Wain J, O'grady J. MinION nanopore sequencing identifies the position and structure of a bacterial antibiotic resistance island. Nat Biotechnol 2015;33:296-300.

15. Schneider GF, Dekker C. DNA sequencing with nanopores. Nat Biotechnol 2012;30:326-8.

16. Damodaran S, Berger MF, Roychowdhury S. Clinical tumor sequencing: opportunities and challenges for precision cancer medicine. American Society of Clinical Oncology Education Book; 2015:e175-82.
17. Bodi K, Perera AG, Adams PS, Bintzler D, Dewar K, Grove DS, Kieleczawa J, Lyons RH, Neubert TA, Noll AC, Singh S, Steen R, Zianni M. Comparison of commercially available target enrichment methods for next-generation sequencing. J Biomol Tech 2013;24:73-86.

18. Mamanova L, Coffey AJ, Scott CE, Kozarewa I, Turner EH, Kumar A, Howard E, Shendure J, Turner DJ. Target-enrichment strategies for next-generation sequencing. Nat Methods 2010;7:111-18.

19. Carr TH, McEwen R, Dougherty B, Johnson JH, Dry JR, Lai Z, Ghazoui Z, Laing NM, Hodgson DR, Cruzalegui F, Hollingsworth SJ, Barrett JC. Defining actionable mutations for oncology therapeutic development. Nat Rev Cancer 2016;16:319-29.

20. Susswein LR, Marshall ML, Nusbaum R, Vogel Postula KJ, Weissman SM, Yackowski L, Vaccari EM, Bissonnette J, Booker JK, Cremona ML, Gibellini F, Murphy PD, Pineda-Alvarez DE, Pollevick GD, Xu Z, Richard G, Bale S, Klein RT, Hruska KS1, Chung WK. Pathogenic and likely pathogenic variant prevalence among the first 10,000 patients referred for next-generation cancer panel testing. Genet Med Genet Med 2015. [Epub ahead of print]. doi: 10.1038/gim.2015.166.

21. Schroeder C, Faust U, Sturm M, Hackmann K, Grundmann K, Harmuth F, Bosse K, Kehrer M, Benkert T, Klink B, Mackenroth L, Betcheva-Krajcir E, Wimberger P, Kast K, Heilig M, Nguyen HP, Riess O, Schröck E, Bauer P, Rump A. HBOC multi-gene panel testing: comparison of two sequencing centers. Breast Cancer Res Treat 2015;152:129-36.

22. Roeder I, Horn K, Sieburg HB, Cho R, Muller-Sieburg C, Loeffler M. Characterization and quantification of clonal heterogeneity among hematopoietic stem cells: a model-based approach. Blood 2008;112:4874-83.

23. Janku F. Tumor heterogeneity in the clinic: is it a real problem? Ther Adv Med Oncol 2014;6:43-51.

24. Cheng DT, Mitchell TN, Zehir A, Shah RH, Benayed R, Syed A, Chandramohan R, Liu ZY, Won HH, Scott SN, Brannon AR, O'reilly C, Sadowska J, Casanova J, Yannes A, Hechtman JF, Yao J, Song W, Ross DS, Oultache A, Dogan S, Borsu L, Hameed M, Nafa K, Arcila ME, Ladanyi M, Berger MF. Memorial Sloan Kettering-Integrated Mutation Profiling of Actionable Cancer Targets (MSK-IMPACT): a hybridization capture-based next-generation sequencing clinical assay for solid tumor molecular oncology. J Mol Diagn 2015;17:251-64.

25. Maggi E, Montagna C. AACR precision medicine series: highlights of the integrating clinical genomics and cancer therapy meeting. Mutat Res 2015;782:44-51.

26. Nadauld L, Van Norman SB, Fulde G, McDermott JG, Newman D, Butler AM, Tudor BP, Gilbert H, Lin KY, Stone G, Ford JM, Haslem DS. Precision medicine to improve survival without increasing costs in advanced cancer patients. J Clin Oncol 2015;33. (suppl):abstr e17641.2015 ASCO annual meeting.

27. Sukhai MA, Craddock KJ, Thomas M, Hansen AR, Zhang T, Siu L, Bedard P, Stockley TL, Kamel-Reid S. A classification system for clinical relevance of somatic variants identified in molecular profiling of cancer. Genet Med 2016;18:128-36.

28. Cristofanilli M, Budd GT, Ellis MJ, Stopeck A, Matera J, Miller MC, Reuben JM, Doyle GV, Allard WJ, Terstappen LW, Hayes DF. Circulating tumor cells, disease progression, and survival in metastatic breast cancer. N Engl J Med 2004;351:781-91.

29. Murtaza M, Dawson SJ, Tsui DW, Gale D, Forshew T, Piskorz AM, Parkinson C, Chin SF, Kingsbury Z, Wong AS, Marass F, Humphray S, Hadfield J, Bentley D, Chin TM, Brenton JD, Caldas C, Rosenfeld N. Non-invasive analysis of acquired resistance to cancer therapy by sequencing of plasma DNA. Nature 2013;497:108-12.

30. Aarthy R, Mani S, Velusami S, Sundarsingh S, Rajkumar T. Role of circulating cell-free DNA in cancers. Mol Diagn Ther 2015;19:339-50.

31. Jahr S, Hentze H, Englisch S, Hardt D, Fackelmayer FO, Hesch RD, Knippers R. DNA fragments in the blood plasma of cancer patients: 
quantitations and evidence for their origin from apoptotic and necrotic cells. Cancer Res 2001;61:1659-65.

32. Belic J, Koch M, Ulz P, Auer M, Gerhalter T, Mohan S, Fischereder K, Petru E, Bauernhofer T, Geigl JB, Speicher MR, Heitzer E. Rapid identification of plasma DNA samples with increased ctDNA levels by a modified FAST-SeqS approach. Clin Chem 2015;61:838-49.

33. Forshew T, Murtaza M, Parkinson C, Gale D, Tsui DW, Kaper F, Dawson SJ, Piskorz AM, Jimenez-Linan M, Bentley D, Hadfield J, May AP, Caldas C, Brenton JD, Rosenfeld N. Noninvasive identification and monitoring of cancer mutations by targeted deep sequencing of plasma DNA. Sci Transl Med 2012;4:136ra68.

34. Kinde I, Wu J, Papadopoulos N, Kinzler KW, Vogelstein B. Detection and quantification of rare mutations with massively parallel sequencing. Proc Natl Acad Sci U S A 2011;108:9530-5.

35. Ashworth TR. A case of cancer in which cells similar to those in the tumors were seen in the blood after death. Aust Med J 1869;14:146-9.

36. Aggarwal C, Meropol NJ, Punt CJ, Iannotti N, Saidman BH, Sabbath KD, Gabrail NY, Picus J, Morse MA, Mitchell E, Miller MC, Cohen SJ. Relationship among circulating tumor cells, CEA and overall survival in patients with metastatic colorectal cancer. Ann Oncol 2013;24:420-8.

37. de Bono JS, Scher HI, Montgomery RB, Parker C, Miller MC, Tissing H, Doyle GV, Terstappen LW, Pienta KJ, Raghavan D. Circulating tumor cells predict survival benefit from treatment in metastatic castration-resistant prostate cancer. Clin Cancer Res 2008;14:6302-9.

38. Heitzer E, Auer M, Gasch C, Pichler M, Ulz P, Hoffmann EM, Lax S, Waldispuehl-Geigl J, Mauermann O, Lackner C, Höfler G, Eisner F, Sill H, Samonigg H, Pantel K, Riethdorf S, Bauernhofer T, Geigl JB, Speicher MR. Complex tumor genomes inferred from single circulating tumor cells by array-CGH and next-generation sequencing. Cancer Res 2013;73:2965-75.

39. Fernandez SV, Bingham C, Fittipaldi P, Austin L, Palazzo J, Palmer G, Alpaugh K, Cristofanilli M. TP53 mutations detected in circulating tumor cells present in the blood of metastatic triple negative breast cancer patients. Breast Cancer Res 2014;16:445.

40. Lohr JG, Adalsteinsson VA, Cibulskis K, Choudhury AD, Rosenberg M, Cruz-Gordillo P, Francis JM, Zhang CZ, Shalek AK, Satija R, Trombetta JJ, Lu D, Tallapragada N, Tahirova N, Kim S, Blumenstiel B, Sougnez C, Lowe A, Wong B, Auclair D, Van Allen EM, Nakabayashi M, Lis RT, Lee GS, Li T, Chabot MS, Ly A, Taplin ME, Clancy TE, Loda M, Regev A, Meyerson M, Hahn WC, Kantoff PW, Golub TR, Getz G, Boehm JS, Love JC. Whole-exome sequencing of circulating tumor cells provides a window into metastatic prostate cancer. Nat Biotechnol 2014;32:479-84.

41. Guttery DS, Page K, Hills A, Woodley L, Marchese SD, Rghebi B, Hastings RK, Luo J, Pringle JH, Stebbing J, Coombes RC, Ali S, Shaw JA. Noninvasive detection of activating estrogen receptor 1 (ESR1) mutations in estrogen receptor-positive metastatic breast cancer. Clin Chem 2015;61:974-82.

42. Paolillo C, Mu Z, Austin L, Nguyen T, Capoluongo DE, Fortina P, Cristofanilli M. Detection of activating estrogen receptor 1 (ESR1) mutation on single circulating tumor cells from metastatic breast cancer patients. 38th Annual SABCS 2015, San Antonio (abstr P2-02-11): http://www.abstracts2view.com/sabcs15/Accessed June 2016.

43. Richards S, Aziz N, Bale S, Bick D, Das S, Gastier-Foster J, Grody WW, Hegde M, Lyon E, Spector E, Voelkerding K, Rehm HL. Standards and guidelines for the interpretation of sequence variants: a joint consensus recommendation of the American College of Medical Genetics and Genomics and the Association for Molecular Pathology. Genet Med 2015;17:405-24.

44. Gargis AS, Kalman L, Berry MW, Bick DP, Dimmock DP, Hambuch T, Lu F, Lyon E, Voelkerding KV, Zehnbauer BA, Agarwala R, Bennett SF, Chen B, Chin EL, Compton JG, Das S, Farkas DH, Ferber MJ, Funke BH, Furtado MR, Ganova-Raeva LM, Geigenmüller U, Gunselman SJ, Hegde MR, Johnson PL, Kasarskis A, Kulkarni S, Lenk T, Liu CS, Manion M, Manolio TA, Mardis ER, Merker JD, Rajeevan MS, Reese MG, Rehm HL, Simen BB, Yeakley JM, Zook JM, Lubin IM. Assuring the quality of next-generation sequencing in clinical laboratory practice. Nat Biotechnol 2012;30:1033-6.

45. Singh RR, Patel KP, Routbort MJ, Aldape K, Lu X, Manekia J, Abraham R, Reddy NG, Barkoh BA, Veliyathu J, Medeiros LJ, Luthra R. Clinical massively parallel next-generation sequencing analysis of 409 cancer-related genes for mutations and copy number variations in solid tumours. Br J Cancer 2014;111:2014-23.

46. Green RC, Berg JS, Grody WW, Kalia SS, Korf BR, Martin CL, McGuire AL, Nussbaum RL, O'daniel JM, Ormond KE, Rehm HL, Watson MS, Williams MS, Biesecker LG. ACMG recommendations for reporting of incidental findings in clinical exome and genome sequencing. Genet Med 2013;15:565-74.

47. Robson ME, Bradbury AR, Arun B, Domchek SM, Ford JM, Hampel HL, Lipkin SM, Syngal S, Wollins DS, Lindor NM. American society of clinical oncology policy statement update: genetic and genomic testing for cancer susceptibility. J Clin Oncol 2015;33:3660-7.

48. Friedman AA, Letai A, Fisher DE, Flaherty KT. Precision medicine for cancer with next-generation functional diagnostics. Nat Rev Cancer 2015;15:747-56. 